\title{
Capacidade funcional de membros superiores em pacientes com câncer de mama
}

\section{Functional capacity of upper limbs in patients with breast cancer}

\author{
Lorena Alves Jesus', Ivana Spínola Cedraz ${ }^{2}$, Alena Peixoto Medrado ${ }^{3}$ \\ 'Universidade Federal da Bahia. Salvador, Bahia, Brasil. ORCID: 0000-0003-4533-4920. lorenalaves7@hotmail.com \\ ${ }^{2}$ Centro de Oncologia do Estado da Bahia. Salvador, Bahia, Brasil. \\ ORCID 0000-0002-5280-5711.ivanacedraz@ig.com.br \\ ${ }^{3}$ Autora para correspondência. Universidade Federal da Bahia e Escola Bahiana de Medicina e Saúde Pública. Salvador, Bahia, Brasil. \\ ORCID: 0000-0003-4074-4680.apmedrado@bahiana.edu.br
}

RESUMO I INTRODUÇÃO: O câncer de mama é o tipo de câncer que mais acomete as mulheres em todo - mundo. Complicações decorrentes do tratamento oncológico para esta neoplasia, a exemplo da redução da amplitude de movimento dos membros envolvidos, devem ser consideradas como relevantes, pois podem prejudicar - retorno às atividades rotineiras, e comprometer a qualidade de vida das pacientes. OBJETIVO: Realizar uma análise funcional de membros superiores de pacientes submetidas ao tratamento cirúrgico do câncer de mama, além descrever as características socioeconômicas e clínica dessa população. MÉTODOS: Tratou-se de um estudo analítico observacional transversal que utilizou uma amostra por conveniência de trinta e uma pacientes submetidas ao tratamento cirúrgico do câncer de mama em tratamento fisioterapêutico no âmbito ambulatorial. Como instrumento para a coleta de dados das pacientes, foi aplicado o questionário Disability Arm Shoulder and Hand (DASH) e realizada uma análise descritiva das variáveis do estudo por meio de medidas de tendência central e de dispersão para as variáveis contínuas e frequências relativa e absoluta para as variáveis categóricas. RESULTADOS: As pacientes entrevistadas apresentaram média de idade de $51 \pm 7$ anos. O tratamento fisioterapêutico ambulatorial ocorreu em um período menor ou igual a sete meses após a cirurgia $(51,6 \%)$. A média total do escore final

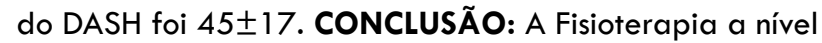
ambulatorial, mesmo iniciada de forma tardia, interferiu positivamente na capacidade funcional dos membros superiores após a cirurgia do câncer de mama.

PALAVRAS-CHAVE: Câncer. Fisioterapia. Neoplasias. Oncologia. Câncer de mama.

\begin{abstract}
INTRODUCTION: Breast cancer is a type of cancer that affects women worldwide. Complications of this cancer treatment, such as the reduction of upper members movement should be considered as relevant, as they may harm the return to daily activities, and compromise the patients' quality of life. OBJECTIVE: To perform a functional analysis of upper limbs of patients undergoing surgical treatment for breast cancer, and describe sociodemographic and clinical characteristics of this population. METHODS: This was a cross-sectional observational analytic study that compromised a convenience sample of thirty-one patients undergoing surgical treatment for breast cancer and they were also submitted to Physiotherapy on ambulatory. It was used the questionnaire Disability Arm Shoulder and Hand (DASH) in order to perform a descriptive analysis of the study variables using measures of central tendency and dispersion for continuous variables and frequencies relative and absolute for categorical variables. RESULTS: The interviewed patients had a mean of $51 \pm 7$ years old. Physiotherapy approach occurred in a period less than or equal to seven months after surgery (51.6\%). The total average final score of DASH was $45 \pm 17$. CONCLUSION: Physiotherapy treatment, even started belatedly, had a positive influence on the functional capacity of the upper limbs after surgery for breast cancer.
\end{abstract}

KEYWORDS: Cancer. Physiotherapy. Neoplasms. Oncology. Breast cancer. 


\section{Introdução}

O câncer de mama é o tipo de câncer que mais acomete as mulheres em todo o mundo e possui maior mortalidade na população feminina, tanto em países em desenvolvimento quanto em desenvolvidos'. A depender do grau de estadiamento, este tipo de câncer pode ter um bom prognóstico, se diagnosticado precocemente e tratado com rapidez. As taxas de mortalidade por este tipo de neoplasia maligna continuam elevadas no Brasil em virtude do fato de que a maioria dos casos da doença ainda é diagnosticada em estágios avançados. No entanto, segundo fontes do Instituto Nacional do Câncer na América do Sul, particularmente no Brasil, a sobrevida de pacientes com câncer tem aumentado, sendo estimada em $87 \%$ no último período do levantamento'.

Atualmente, o tratamento padrão para o câncer de mama em estágios iniciais engloba cirurgia conservadora e por vezes, abordagem cirúrgica de linfonodos axilares, seguida ou não de radio e quimioterapia ${ }^{2}$. Já nos estádios mais avançados, sempre é utilizado o tratamento sistêmico com quimioterapia e hormonioterapia, no sentido de controlar o potencial de metástase para outros sítios do organismo ${ }^{3}$.

Independente da abordagem cirúrgica utilizada, seja ela radical ou conservadora, existem inúmeras complicações decorrentes do tratamento as quais têm sido descritas como sensações dolorosas, incapacitantes e desagradáveis que podem dificultar a recuperação das pacientes. É de fundamental importância o estudo sobre o comportamento destas intercorrências, uma vez que a abordagem fisioterapêutica adequada pode auxiliar na reabilitação funcional desta população ${ }^{4}$.

De um modo geral, a funcionalidade está relacionada com as atividades desempenhadas na vida diária de cada indivíduo. As complicações decorrentes do tratamento oncológico para o câncer de mama, a exemplo do linfedema, da dor, parestesia, diminuição da força muscular e redução da amplitude de movimento (ADM) dos membros envolvidos, podem prejudicar o desempenho das atividades cotidianas, e comprometer a qualidade de vida das pacientes ${ }^{3}$.
Diante do exposto, o objetivo deste estudo é realizar uma análise da funcionalidade dos membros superiores de mulheres submetidas ao tratamento cirúrgico do câncer de mama, no âmbito ambulatorial, acompanhadas por Fisioterapeutas nos setores público e privado na cidade de Salvador-BA. Adicionalmente, objetiva descrever as características socioeconômicas e clínicas dessa população.

\section{Material e métodos}

Tratou-se de um estudo analítico observacional transversal que utilizou uma amostra por conveniência de mulheres submetidas ao tratamento cirúrgico do câncer de mama de uma clínica privada e do Centro de Oncologia do Estado da Bahia (CICAN), ambos localizados no município de Salvador - Bahia.

Este estudo foi aprovado pelo Comitê de Ética e Pesquisa (CEP) do Instituto de Ciências da Saúde da Universidade Federal da Bahia (UFBA) na cidade de Salvador- BA, sob número de protocolo 2.080.047 e número do CAAE: 42839214.1.0000.5662. Todas as participantes assinaram um Termo de Consentimento Livre e Esclarecido. A pesquisa foi realizada de acordo com a resolução CNS 196/06 e compreendeu o período de um ano (2014-2015).

Foram incluídas neste estudo trinta e uma mulheres submetidas ao tratamento cirúrgico há um ano ou mais, acompanhadas por Fisioterapeutas no âmbito ambulatorial e que respondessem a 27 ou mais perguntas delineadas no instrumento de avaliação. Foram adotados como critérios de exclusão pacientes que apresentaram déficit cognitivo ou que fossem portadoras de outras doenças sistêmicas a exemplo de diabetes, hipertensão arterial maligna, síndromes genéticas, cardiopatias, síndrome nefrótica, infecções bacterianas e/ou virais e lesões pré-existentes do plexo braquial. Apenas duas pacientes foram excluídas do estudo por não se encaixarem nos critérios de inclusão adotados na pesquisa.

Como instrumento para a coleta foi utilizado o questionário Disability Arm Shoulder and Hand (DASH) para mensuração da funcionalidade do 
membro superior destas mulheres, instrumento este já validado na literatura 5 . O DASH é um questionário adaptado para a população brasileira que contém 30 questões, com valor máximo de cinco. O escore total foi calculado através da soma das 30 primeiras questões divido por 1,2. As perguntas desse questionário normalmente abordam aspectos relacionados à função física, sintomas e impacto no desempenho da função social da paciente na última semana precedente à realização da entrevista. Foram necessários, no mínimo, 27 itens respondidos para validar a participação das pacientes. Este questionário ainda possui dois módulos opcionais (Performance musical ou esportiva e trabalho), os quais não foram utilizados no presente estudo, uma vez que fugiam ao escopo da pesquisa.

Foram coletadas também as seguintes variáveis descritivas: idade, escolaridade, estado civil, ocupação, lado dominante, tipo de cirurgia mamária, se houve reconstrução mamária, tempo transcorrido entre a cirurgia e o início da Fisioterapia, e os tratamentos oncológicos realizados (quimioterapia, radioterapia e hormonioterapia). Foi realizada uma análise descritiva das variáveis pertencentes ao estudo por meio das medidas de tendência central (média) e medidas de dispersão (desvio-padrão) para as variáveis contínuas e frequência relativa e absoluta, para as variáveis dicotômicas. Para análise dos dados, foi utilizado o pacote estatístico SPSS 17.0 (Statistical Package for the Social Sciences).

\section{Resultados}

As pacientes entrevistadas apresentaram média de idade de $51 \pm 7$ anos, e eram, em sua maioria, solteiras $(58,1 \%)$, que tinham o primeiro ou segundo grau completo $(38,7 \%)$. Cerca de trinta e dois por cento das entrevistadas, estavam afastadas das suas atividades laborais. $O$ lado dominante foi o direito $(93,6 \%)$ que predominantemente correspondia ao mesmo lado da abordagem cirúrgica (54,9\%). A maioria das mulheres entrevistadas realizava a Fisioterapia pelo Sistema Único de Saúde no Estado da Bahia (SUS/ BA) $(80,6 \%)$, Quadro 1.

Em relação às variáveis cirúrgicas e da terapêutica oncológica, a maior parte foi submetida à mastectomia radical $(67,7 \%)$. A reconstrução da mama foi realizada em $16,2 \%$ dos casos com uso de prótese de silicone. Considerando-se as modalidades de terapias sistêmicas, a quimioterapia adjuvante foi realizada em $96,8 \%$ dos casos, a radioterapia em $80,6 \%$ e a hormonioterapia em $67,7 \%$. O tratamento fisioterapêutico ambulatorial ocorreu em um período menor ou igual a sete meses após a cirurgia $(51,6 \%)$. Ao serem questionadas sobre as orientações fisioterapêuticas antes da cirurgia, apenas $16,2 \%$ relataram terem recebido tais orientações, Quadro 2.

As características funcionais dos membros superiores foram analisadas pelo questionário DASH. Entre as atividades que as pacientes classificaram como havendo muita dificuldade em realizar foram listadas as seguintes categorias: Atividades recreativas que exigiam força ou impacto nos braços, ombros ou mãos $(32,3 \%)$ e realização de tarefas domésticas pesadas $(25,9 \%)$. As atividades que foram classificadas como não havendo dificuldade em realizar incluíram: Escrever (90,4\%), virar uma chave $(96,8 \%)$, preparar uma refeição $(70,9 \%)$ e atividades recreativas que exigiam pouco esforço (jogar cartas, tricotar) $(80,7 \%)$. Entre outras tarefas que foram classificadas como não fáceis de realizar pode-se citar arrumar a cama $(64,6 \%)$, lavar ou secar o cabelo $(51,8 \%)$, usar uma faca para cortar alimentos $(67,8 \%)$, transportar-se de um lado para outro (ir de um lugar ao outro) $(54,8 \%$ ) e atividades sexuais $(58,3 \%)$, Quadro 3.

Cerca de $84 \%$ das entrevistadas relataram que na semana passada à entrevista, o problema com braço, ombro ou mão não havia afetado suas atividades normais sociais com a família, amigos, vizinhos e colegas e $51,8 \%$ delas relataram que o seu trabalho ou suas atividades diárias cotidianas não foram limitadas devido ao seu problema com braço, ombro ou mão Quadro 4.

Muitas pacientes relataram não sentir nenhuma dor espontânea ou pouca dor no braço, ombro ou mão $(41,8 \%$ e $19,4 \%$, respectivamente). Ao realizarem alguma atividade específica, 32,3\% das pacientes não se queixaram de dor, $58 \%$ relataram grau baixo ou médio de dor e apenas $9 \%$ descreveram dor severa. No que tange ao desconforto na pele (alfinetadas) nos membros superiores $41,9 \%$ relataram não sentir tal sintoma, 
porém $6 \%$ das entrevistadas relataram sentir pouca e mediana dor respectivamente. Quarenta e dois por cento das pacientes não referiram fraqueza no braço, ombro ou mão, entretanto $32,2 \%$ relataram pouca fraqueza e somente $16,1 \%$ relatarem muita fraqueza. Quando questionadas sobre a dificuldade em mover os membros superiores, $41,9 \%$ não relataram dificuldade, $16,1 \%$ pouca dificuldade e $29 \%$ responderam que sentiam dificuldade mediana, Quadro 5.
As pacientes relataram também que não houve dificuldade no trabalho ou desempenho de atividades diárias normais devido ao seu problema com os membros superiores $(61,2 \%)$. Sobre como se sentiam em relação aos problemas com braço, ombro ou mão, $29 \%$ das mulheres responderam que discordavam totalmente da seguinte afirmação: "Eu me sinto menos capaz, menos confiante e menos útil por causa do meu problema com braço, ombro e mão",. A média total do escore final do DASH foi

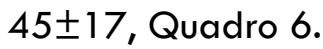

Quadro 1. Análise descritiva das variáveis sociodemográficas e clínicas em pacientes com câncer de mama. Salvador/BA, 2017.

\begin{tabular}{|c|c|c|}
\hline Variável & $\mathrm{N}$ & $\%$ \\
\hline \multicolumn{3}{|l|}{ Idade (anos) } \\
\hline$<50$ anos & 11 & $35,5 \%$ \\
\hline$\geq 50$ anos & 20 & $64,5 \%$ \\
\hline \multicolumn{3}{|l|}{ Estado Civil } \\
\hline Solteira & 18 & $58,1 \%$ \\
\hline Divorciada & 1 & $3,2 \%$ \\
\hline Viúva & 2 & $6,5 \%$ \\
\hline Casadas & 10 & $32,3 \%$ \\
\hline \multicolumn{3}{|l|}{ Nível de escolaridade } \\
\hline Analfabeto & 0 & $0 \%$ \\
\hline Primeiro grau incompleto & 1 & $3,2 \%$ \\
\hline Primeiro grau completo & 12 & $38,7 \%$ \\
\hline Segundo grau incompleto & 1 & $3,2 \%$ \\
\hline Segundo grau completo & 12 & $38,7 \%$ \\
\hline Superior incompleto & 5 & $16,1 \%$ \\
\hline \multicolumn{3}{|l|}{ Ocupação } \\
\hline Do lar & 9 & $29,0 \%$ \\
\hline Trabalha fora do lar & 9 & $29,0 \%$ \\
\hline Afastada & 10 & $32,3 \%$ \\
\hline Aposentada & 3 & $9,7 \%$ \\
\hline \multicolumn{3}{|l|}{ Lado dominante } \\
\hline Direito & 29 & $93,5 \%$ \\
\hline Esquerdo & 2 & $6,5 \%$ \\
\hline \multicolumn{3}{|c|}{$\begin{array}{l}\text { O lado dominante é o mesmo da } \\
\text { cirurgia? }\end{array}$} \\
\hline Sim & 17 & $54,8 \%$ \\
\hline Não & 14 & $45,2 \%$ \\
\hline \multicolumn{3}{|l|}{$\begin{array}{l}\text { Instituição de Atendimento } \\
\text { Fisioterapêutico }\end{array}$} \\
\hline Público & 25 & $80,6 \%$ \\
\hline Particular & 6 & $19,4 \%$ \\
\hline
\end{tabular}


Quadro 2. Análise descritiva das variáveis cirúrgicas e terapêuticas oncológicas para o câncer de mama. Salvador/ BA, 2017.

\begin{tabular}{|c|c|c|}
\hline Variável & $\mathrm{N}$ & $\%$ \\
\hline \multicolumn{3}{|l|}{ Tipo de cirurgia } \\
\hline Mastectomia Radical & 21 & $67,7 \%$ \\
\hline Conservadora & 7 & $22,6 \%$ \\
\hline Conservadora/ mastectomia & 3 & $9,7 \%$ \\
\hline \multicolumn{3}{|l|}{ Reconstrução mamária } \\
\hline Sim & 5 & $16,1 \%$ \\
\hline Não & 26 & $83,9 \%$ \\
\hline \multicolumn{3}{|l|}{ Quimioterapia Adjuvante } \\
\hline Sim & 30 & $96,8 \%$ \\
\hline Não & 1 & $3,2 \%$ \\
\hline \multicolumn{3}{|l|}{ Radioterapia Adjuvante } \\
\hline Sim & 25 & $80,6 \%$ \\
\hline Não & 6 & $19,4 \%$ \\
\hline \multicolumn{3}{|l|}{ Hormonioterapia Adjuvante } \\
\hline Sim & 21 & $67,7 \%$ \\
\hline Não & 10 & $32,3 \%$ \\
\hline \multicolumn{3}{|c|}{$\begin{array}{l}\text { Começo da Fisiołerapia após a } \\
\text { abordagem cirurgica }\end{array}$} \\
\hline$<=7$ meses & 16 & $51,6 \%$ \\
\hline 1 ano & 11 & $35,5 \%$ \\
\hline$>1$ ano & 4 & $12,9 \%$ \\
\hline \multicolumn{3}{|l|}{$\begin{array}{l}\text { Orientação Fisiołerapeutica } \\
\text { antes da cirurgia }\end{array}$} \\
\hline Sim & 5 & $16,1 \%$ \\
\hline Não & 26 & $83,9 \%$ \\
\hline
\end{tabular}


Quadro 3. Pontuação da DASH de acordo com a habilidade em realizar atividades cotidianas referentes às respostas das pacientes com câncer de mama. Salvador/BA, 2017.

\begin{tabular}{|c|c|c|c|c|c|c|c|}
\hline $\begin{array}{c}\text { Meça a sua habilidade em fazer as seguintes } \\
\text { atividades na semana passada: }\end{array}$ & $\begin{array}{c}\text { Não houve } \\
\text { dificuldade } \\
n(\%)\end{array}$ & $\begin{array}{c}\text { Houve pouca } \\
\text { dificuldade } \\
n(\%)\end{array}$ & $\begin{array}{c}\text { Houve } \\
\text { dificuldade } \\
\text { média } \\
\mathrm{n}(\%)\end{array}$ & $\begin{array}{c}\text { Houve muita } \\
\text { dificuldade } \\
n(\%)\end{array}$ & $\begin{array}{c}\text { Não conseguiu } \\
\text { fazer } \\
n(\%)\end{array}$ & $\begin{array}{c}\text { Não } \\
\text { Opinou } \\
n(\%)\end{array}$ & $\begin{array}{c}\text { Média e } \\
\text { desvio Padrão } \\
\mathrm{n}(\%)\end{array}$ \\
\hline Abrir um vidro novo com uma tampa muito apertada & $9(29,0 \%)$ & $6(19,4 \%)$ & $11(35,5 \%)$ & $2(6,5 \%)$ & $3(9,7 \%)$ & -. & $2,48 \pm 1,26$ \\
\hline Escrever & $28(90,3 \%)$ & $1(3,2 \%)$ & $1(3,2 \%)$ & $1(3,2 \%)$ & -. & -. & $1 \pm 0$ \\
\hline Virar uma chave & $30(96,8 \%)$ & $1(3,2 \%)$ & $-\cdot$ & -- & $-\cdot$ & -- & $1 \pm 0$ \\
\hline Preparar uma refeição & $22(71 \%)$ & $5(16,1 \%)$ & $1(3,2 \%)$ & $3(9,7 \%)$ & -. & -. & $1 \pm 0$ \\
\hline Abrir uma porta pesada & $10(32,3 \%)$ & $9(29 \%)$ & $4(12,9 \%)$ & $6(19,4 \%)$ & $2(6,5 \%)$ & -. & $2 \pm 1,41$ \\
\hline Colocar algo em uma prateleira acima de sua cabeça & $15(48,4 \%)$ & $8(25,8 \%)$ & $4(12,9 \%)$ & $3(9,7 \%)$ & $1(3,2 \%)$ & -. & $1 \pm 0$ \\
\hline $\begin{array}{c}\text { Fazer tarefas domésticas pesadas (por exemplo: } \\
\text { lavar paredes, lavar o chão) }\end{array}$ & $7(22,6 \%)$ & $6(19,4 \%)$ & $5(16,1 \%)$ & $8(25,8 \%)$ & $4(12,9 \%)$ & $1(3,2 \%)$ & $2,5 \pm 2,12$ \\
\hline Fazer trabalho de jardinagem & $17(54,8 \%)$ & $6(19,4 \%)$ & $3(9,7 \%)$ & $2(6,5 \%)$ & $3(9,7 \%)$ & .. & $3 \pm 2,82$ \\
\hline Arrumar a cama & $20(64,5 \%)$ & $4(12,9 \%)$ & $4(12,9 \%)$ & $1(3,2 \%)$ & $2(6,5 \%)$ & .. & $2 \pm 1,41$ \\
\hline Carregar uma sacola ou uma maleta & $14(45,2 \%)$ & $6(19,4 \%)$ & $6(19,4 \%)$ & $3(9,7 \%)$ & $1(3,2 \%)$ & $1(3,2 \%)$ & $1 \pm 1,41$ \\
\hline Carregar um objeto pesado (mais de $5 \mathrm{~kg}$ ) & $4(12,9 \%)$ & $5(16,1 \%)$ & $4(12,9)$ & $8(25,8 \%)$ & $8(25,8 \%)$ & $2(6,5 \%)$ & $2,5 \pm 3,5$ \\
\hline Trocar uma lâmpada acima da cabeça & $13(41,9 \%)$ & $5(16,1 \%)$ & $4(12,9 \%)$ & $3(9,7 \%)$ & $6(19,4 \%)$ & .. & $3 \pm 2,8$ \\
\hline Lavar ou secar o cabelo & $16(51,6 \%)$ & $7(22,6 \%)$ & $5(16,1 \%)$ & $2(6,5 \%)$ & $1(3,2 \%)$ & .- & $2,5 \pm 2,12$ \\
\hline Lavar suas costas & $10(32,3 \%)$ & $8(25,8 \%)$ & $5(16,1 \%)$ & $7(22,6 \%)$ & $1(3,2 \%)$ & .. & $2,38 \pm 1,25$ \\
\hline Vestir uma blusa fechada & $15(48,4 \%)$ & $7(22,6 \%)$ & $3(9,7 \%)$ & $6(19,4 \%)$ & .. & .. & $3 \pm 1,41$ \\
\hline Usar uma faca pra cortar alimentos & $21(67,7 \%)$ & $6(19,4 \%)$ & $1(3,2 \%)$ & $2(6,5 \%)$ & $1(3,2 \%)$ & .. & $1 \pm 0$ \\
\hline $\begin{array}{c}\text { Atividades recreativas que exigem pouco esforço } \\
\text { (jogar cartas, tricotar) }\end{array}$ & $25(80,6 \%)$ & $2(6,5 \%)$ & $3(9,7 \%)$ & $-\cdot$ & -. & $1(3,2 \%)$ & $0,5 \pm 0,70$ \\
\hline $\begin{array}{l}\text { Atividades recreativas que exigem força ou impacto } \\
\text { nos braços, ombros ou mãos (jogar vôlei, martelar) }\end{array}$ & $4(12,9 \%)$ & $3(9,7 \%)$ & $3(9,7 \%)$ & $10(32,3 \%)$ & $10(32,3 \%)$ & $1(3,2 \%)$ & $1,5 \pm 0,70$ \\
\hline $\begin{array}{l}\text { Atividades recreativas nas quais você move seu braço } \\
\text { livremente (como: pescar, jogar) }\end{array}$ & $6(19,4 \%)$ & $3(9,7 \%)$ & $6(19,4 \%)$ & $9(29,0 \%)$ & $6(19,4 \%)$ & $1(3,2 \%)$ & $1 \pm 1,41$ \\
\hline $\begin{array}{l}\text { Transportar-se de um lado para outro (ir de um lugar } \\
\text { a outro) }\end{array}$ & $17(54,8 \%)$ & $5(16,1 \%)$ & $3(9,7 \%)$ & $5(16,1 \%)$ & $1(3,2 \%)$ & -- & $1 \pm 0$ \\
\hline Atividades sexuais & $18(58,1 \%)$ & $1(3,2 \%)$ & $3(9,7 \%)$ & $2(6,5 \%)$ & $\cdot-$ & $\begin{array}{c}7 \\
(22,6 \%)\end{array}$ & $0,5 \pm 0,70$ \\
\hline
\end{tabular}

Quadro 4. Pontuação da DASH de acordo com os sintomas das pacientes com câncer de mama na semana passada a entrevista. Salvador/ BA, 2017.

\begin{tabular}{|c|c|c|c|c|c|c|c|}
\hline $\begin{array}{l}\text { Meça a gravidade dos seguintes } \\
\text { sintomas na semana passada: }\end{array}$ & $\begin{array}{c}\text { Não Afetou } \\
n(\%)\end{array}$ & $\begin{array}{c}\text { Afetou pouco } \\
n(\%)\end{array}$ & $\begin{array}{c}\text { Afetou } \\
\text { medianamente } \\
(\%)\end{array}$ & $\begin{array}{c}\text { Afetou } \\
\text { muito } \\
n(\%)\end{array}$ & $\begin{array}{c}\text { Afetou } \\
\text { extremamente } \\
n(\%)\end{array}$ & $\begin{array}{c}\text { Não } \\
\text { Opinou } \\
n(\%)\end{array}$ & $\begin{array}{l}\text { Média e } \\
\text { desvio } \\
\text { Padrão } \\
\text { n (\%) }\end{array}$ \\
\hline $\begin{array}{c}\text { Na semana passada, em que ponto o } \\
\text { seu problema com braço, ombro ou } \\
\text { mão afetou suas atividades normais } \\
\text { com familia, amigos, vizinhos e } \\
\text { colegas? }\end{array}$ & $26(83,9 \%)$ & $3(9,7 \%)$ & $1(3,2 \%)$ & $1(3,2 \%)$ & -- & -- & $1 \pm 0$ \\
\hline $\begin{array}{l}\text { Meça a gravidade dos seguintes } \\
\text { sintomas na semana passada: }\end{array}$ & $\begin{array}{c}\text { Não limitou } \\
n(\%)\end{array}$ & $\begin{array}{l}\text { Limitou pouco } \\
n(\%)\end{array}$ & $\begin{array}{c}\text { Limitou } \\
\text { medianamente } \\
n(\%)\end{array}$ & $\begin{array}{c}\text { Limitou } \\
\text { muito } \\
n(\%)\end{array}$ & $\begin{array}{c}\text { Não conseguiu } \\
\text { fazer } \\
n(\%)\end{array}$ & $\begin{array}{c}\text { Não } \\
\text { Opinou } \\
n(\%)\end{array}$ & $\begin{array}{l}\text { Média e } \\
\text { desvio } \\
\text { Padrão } \\
\text { n (\%) }\end{array}$ \\
\hline $\begin{array}{c}\text { Durante a semana passada, o seu } \\
\text { trabalho ou atividades diárias } \\
\text { normais foram limitadas devido ao } \\
\text { seu problema com braço, ombro ou } \\
\text { mão? }\end{array}$ & $16(51,6 \%)$ & $9(29,0 \%)$ & $4(12,9 \%)$ & $1(3,2 \%)$ & $1(3,2 \%)$ & -- & $1,5 \pm 0,70$ \\
\hline
\end{tabular}


Quadro 5. Pontuação dos sintomas álgicos do braço, ombro e mão das pacientes com câncer de mama. Salvador/ BA, 2017.

\begin{tabular}{|c|c|c|c|c|c|c|c|}
\hline $\begin{array}{c}\text { Meça a gravidade dos } \\
\text { seguintes sintomas na } \\
\text { semana passada: }\end{array}$ & $\begin{array}{c}\text { Nenhum } \\
\mathrm{n}(\%)\end{array}$ & $\begin{array}{c}\text { Pouca } \\
\mathrm{n}(\%)\end{array}$ & $\begin{array}{c}\text { Mediana } \\
\mathrm{n}(\%)\end{array}$ & $\begin{array}{c}\text { Muita } \\
\mathrm{n}(\%)\end{array}$ & $\begin{array}{c}\text { Extrema } \\
\mathrm{n}(\%)\end{array}$ & $\begin{array}{c}\text { Não Opinou } \\
\mathrm{n}(\%)\end{array}$ & $\begin{array}{c}\text { Média e desvio } \\
\text { Padrão } \\
\mathrm{n}(\%)\end{array}$ \\
\hline Dor no braço, ombro ou mão & $\begin{array}{c}13 \\
(41,9 \%)\end{array}$ & $6(19,4 \%)$ & $10(32,3 \%)$ & $2(6,5 \%)$ & -- & -- & $2 \pm 1,41$ \\
\hline $\begin{array}{c}\text { Dor no braço, ombro ou mão } \\
\text { quando você fazia alguma } \\
\text { atividade específica }\end{array}$ & $\begin{array}{c}10 \\
(32,3 \%)\end{array}$ & $9(29,0 \%)$ & $9(29,0 \%)$ & $3(9,7 \%)$ & -- & $2,5 \pm 0,70$ \\
\hline $\begin{array}{c}\text { Desconforto na pele } \\
\text { (alfinetadas) no braço, ombro } \\
\text { ou mão }\end{array}$ & $\begin{array}{c}13 \% \\
(41,9 \%)\end{array}$ & $6(19,4 \%)$ & $6(19,4 \%)$ & $5(16,1 \%)$ & $1(3,2 \%)$ & -- & $2 \pm 1,41$ \\
\hline $\begin{array}{c}\text { Fraqueza no braço, ombro ou } \\
\text { mão }\end{array}$ & $\begin{array}{c}13 \% \\
(41,9 \%)\end{array}$ & $10(32,3 \%)$ & $3(9,7 \%)$ & $5(16,1 \%)$ & -- & -- & $2 \pm 1,41$ \\
\hline $\begin{array}{c}\text { Dificuldade em mover braço, } \\
\text { ombro ou mão }\end{array}$ & $\begin{array}{c}13 \% \\
(41,9 \%)\end{array}$ & $5(16,1 \%)$ & $9(29,0 \%)$ & $4(12,9 \%)$ & -- & -- & $2 \pm 1,41$ \\
\hline
\end{tabular}

Quadro 6. Pontuação do convívio social das pacientes com câncer de mama. Salvador/ BA, 2017.

\begin{tabular}{|c|c|c|c|c|c|c|c|}
\hline $\begin{array}{l}\text { Meça a gravidade dos } \\
\text { seguintes sintomas na } \\
\text { semana passada: }\end{array}$ & $\begin{array}{c}\text { Não houve } \\
\text { dificuldade } \\
n(\%)\end{array}$ & $\begin{array}{l}\text { Pouco dificuldade } \\
\text { n(\%) }\end{array}$ & $\begin{array}{c}\text { Média } \\
\text { dificuldade } \\
n(\%)\end{array}$ & $\begin{array}{c}\text { Muita } \\
\text { dificuldade } \\
n(\%)\end{array}$ & $\begin{array}{l}\text { Tão difícil que } \\
\text { você não } \\
\text { pôde dormir } \\
n(\%)\end{array}$ & $\begin{array}{c}\text { Não Opinou } \\
n(\%)\end{array}$ & $\begin{array}{c}\text { Média e desvio } \\
\text { Padrão } \\
\text { n (\%) }\end{array}$ \\
\hline \multirow[t]{2}{*}{$\begin{array}{c}\text { Durante a semana } \\
\text { passada, o seu trabalho } \\
\text { ou atividades diárias } \\
\text { normais foram limitados } \\
\text { devido ao seu problema } \\
\text { com braço, ombro ou } \\
\text { mão? }\end{array}$} & $19(61,3 \%)$ & $5(16,1 \%)$ & $1(3,2 \%)$ & $6(19,4 \%)$ & -- & -- & $1 \pm 0$ \\
\hline & $\begin{array}{c}\text { Discordo } \\
\text { totalmente } \\
\text { n (\%) }\end{array}$ & $\begin{array}{c}\text { Discordo } \\
n(\%)\end{array}$ & $\begin{array}{c}\text { Não concordo } \\
\text { nem discordo } \\
n(\%)\end{array}$ & $\begin{array}{c}\text { Concordo } \\
n(\%)\end{array}$ & $\begin{array}{c}\text { Concordo } \\
\text { totalmente } \\
n(\%)\end{array}$ & $\begin{array}{c}\text { Não Opinou } \\
n(\%)\end{array}$ & $\begin{array}{c}\text { Média e desvio } \\
\text { Padrão } \\
\text { n (\%) }\end{array}$ \\
\hline $\begin{array}{l}\text { Eu me sinto menos capaz } \\
\text { menos confiante e menos } \\
\text { útil por causa do meu } \\
\text { problema com braço, } \\
\text { ombro e mão }\end{array}$ & $9(29,0 \%)$ & $6(19,4 \%)$ & $2(6,5 \%)$ & $8(25,8 \%)$ & $6(19,4 \%)$ & -- & $3 \pm 2,82$ \\
\hline
\end{tabular}




\section{Discussão}

A presente investigação objetivou analisar a funcionalidade dos membros superiores de mulheres submetidas ao tratamento cirúrgico do câncer de mama, no âmbito ambulatorial, acompanhadas por Fisioterapeutas nos setores público e privado na cidade de Salvador-BA, e descrever as características socioeconômicas e clínicas dessa população. Sabese que este segmento populacional é representado por 2.760 novos casos por 100 mil habitantes para o ano de 2016 no estado da Bahia. Para a capital Salvador, são esperados 1.000 novos casos'.

Segundo os dados socioeconômicos, as pacientes entrevistadas apresentaram a média de idade 51 \pm 7 anos. De acordo com o INCA, a idade continua sendo um dos principais fatores de risco para o câncer de mama em mulheres. As taxas de incidência aumentam rapidamente até os 50 anos, após essa idade, o aumento ocorre de forma mais lenta. Entretanto, o câncer de mama em mulheres jovens apresenta características clínicas e epidemiológicas bem diferentes das observadas em mulheres mais velhas. Geralmente, são mais agressivos, pois apresentam uma alta taxa de presença da mutação dos genes BRCA1 e BRCA2'.

As pacientes incluídas neste estudo, em sua maioria, realizaram mastectomia radical, abordagem cirúrgica que envolve a remoção da mama, músculos peitorais, fáscia torácica e nodos linfáticos axilares ipsolaterais ${ }^{2}$. Tal abordagem cirúrgica está associada a maiores limitações da funcionalidade de membros6, fato este que instigou o interesse dos autores para a realização deste estudo. Nesta pesquisa, constatou-se um escore da DASH de $45 \pm 17$, o que parece sugerir a ação da Fisioterapia como especialidade integrante do tratamento ambulatorial do câncer de mama, mesmo sendo iniciada em um tempo médio de sete meses após a cirurgia. Deve-se levar em consideração que 54,9\% das pacientes realizaram a abordagem cirúrgica no lado dominante, o que pode ter representado um impedimento para a evolução quanto à capacidade funcional do membro afetado e justificado o escore obtido, em especial, se consideramos o escore final relatado por Souza et al, no qual constatouse escore de 27,07 na amostra de 105 pacientes.
No entanto, tais autores relataram que o protocolo fisioterapêutico iniciou-se imediatamente após a cirurgia, à beira do leito ${ }^{7}$.

O tratamento fisioterapêutico pós-cirúrgico ambulatorial no presente estudo ocorreu em um período menor ou igual há sete meses após a cirurgia. Embora a necessidade do acompanhamento fisioterapêutico após a cirurgia da mama seja amplamente conhecida, muitas mulheres são encaminhadas ao fisioterapeuta tardiamente, quando já apresentam complicações instaladas, o que diminui as chances de uma completa recuperação funcional e um retorno precoce para as atividades8. Ao serem questionadas sobre as orientações fisioterapêuticas antes da cirurgia, apenas 16,2\% relataram terem recebido tais orientações. Esses dados evidenciam a necessidade do Fisioterapeuta atuar na prevenção de complicações no momento pré-cirúrgico e orientar precocemente suas pacientes no período pós-cirúrgico.

Para avaliar a capacidade funcional dos membros superiores os pesquisadores envolvidos nesse estudo optaram pelo questionário Disability Arm Shoulder and Hand. Acredita-se que a DASH represente ser o instrumento mais completo para avaliação da funcionalidade de membros superiores, uma vez que foi $\circ$ mais documentado na literatura e $\circ$ que forneceu o maior número de informações acerca das atividades básicas da vida diária que podem ser comprometidas no período pós-cirúrgico?.

No período pós-operatório, muitas mulheres evoluem com dificuldades relacionadas às atividades instrumentais, básicas e avançadas da vida diária ${ }^{8}$. Os achados observados na presente investigação evidenciaram que as pacientes que estavam em tratamento fisioterapêutico ainda apresentavam limitações para o desempenho das atividades recreativas que exigiam força ou impacto nos braços, ombros ou mãos e para realizar tarefas domésticas pesadas. Tais atividades requerem maiores habilidades. Em contrapartida, atividades como escrever, virar uma chave, preparar uma refeição, atividades recreativas que exigiam pouco esforço, arrumar a cama, lavar ou secar o cabelo, usar uma faca para cortar alimentos, transportar-se de um lado para outro e atividades sexuais foram consideradas de fácil realização. 
Em relação ao convívio com familiares, amigos, vizinhos e colegas, as entrevistadas relataram que os sintomas do ombro, braço e mão não afetaram as relações com os mesmos. Isto pode ser justificado pelos relatos negativos referentes aos sintomas álgicos dos membros superiores e as limitações funcionais. É importante ressaltar que os sintomas álgicos em conjunto com as incapacidades relacionadas à neoplasia e seu tratamento podem causar prejuízo funcional, perda do convívio social, redução das atividades profissionais e de lazer. Os sintomas álgicos não causados pela neoplasia incluem aqueles decorrentes do imobilismo, e consequente redução da amplitude articular. As queixas álgicas podem surgir também devido a anormalidades musculoesqueléticas ou metabólicas, úlceras de decúbito e a permanência em posturas antálgicas por longos períodos ${ }^{10,11}$.

É fundamental afirmar, também, a importância da multidisciplinaridade no tratamento de pacientes após a cirurgia do câncer de mama. As pacientes incluídas no presente estudo, além do profissional Fisioterapeuta contavam com $\circ$ apoio de outros profissionais de saúde a exemplo de nutricionista, psicólogo, enfermeiro, mastologista, oncologista, radioterapeuta e assistente social as quais também foram importantes para a obtenção de bons resultados.

Observou-se que uma limitação do estudo foi representada pelo enfoque restrito relacionado aos achados oncológicos, como o estadiamento dos tumores, a abordagem axilar e a localização da radioterapia, dados esses que não foram descritos em alguns portuários. Some-se a este fato, a pequena população amostral que representou a realidade dos serviços durante o período abrangido pelo estudo. Como sugestão para estudos futuros os pesquisadores salientam a necessidade de ampliação do número de pacientes e dos dados referentes ao estadiamento oncológico dos tumores, a realização ou não de abordagem axilar e radioterapia, uma vez que tais variáveis estão diretamente relacionadas à capacidade funcional dos membros superiores após a abordagem cirúrgica.

\section{Conclusão}

A Fisioterapia a nível ambulatorial, mesmo iniciada de forma tardia, interferiu positivamente na capacidade funcional dos membros superiores após a cirurgia do câncer de mama, principalmente no que tange às atividades básicas e instrumentais desempenhadas pelas pacientes. $O$ presente estudo também evidenciou que as pacientes não relataram sintomas álgicos em ombros, braços ou mãos ou alterações que interferissem dramaticamente no seu convívio social.

\section{Contribuições das autoras}

Jesus LA, Cedraz IS, Medrado AP participaram do desenho de estudo, coleta, análise e interpretação de dados e escrita do artigo.

\section{Conflitos de interesses}

Nenhum conflito financeiro, legal ou político envolvendo terceiros (governo, empresas e fundações privadas, etc.) foi declarado para nenhum aspecto do trabalho submetido (incluindo mas não limitandose a subvenções e financiamentos, conselho consultivo, desenho de estudo, preparação de manuscrito, análise estatística, etc).

\section{Referências}

1. Instituto Nacional de Câncer José Gomes Alencar da Silva. Estimativa 2016: incidência de câncer no Brasil [Internet]. Disponível em: http://www.inca.gov.br/estimativa/2016/

2. Marta GN, Hanna AS, Martella E, da Silva JLF, Carvalho HA. Câncer de mama estádio inicial e radioterapia: atualização. Rev Assoc Med Bras. 2011 ;57(4):468-74. doi: $10.1590 /$ S0104-42302011000400024

3. Majewski JM, Lopes ADF, Davoglio T, Leite JCC. Qualidade de vida em mulheres submetidas à mastectomia comparada com aquelas que se submeteram a cirurgia conservadora: uma revisão de literatura. Ciênc e saúde colet. 2012 ; 17(3):707-716. doi: 10.1590/S1413$\underline{81232012000300017}$

4. Camargo MC, Marx AG. Reabilitação física no câncer de mama. São Paulo: Roca; 2000. 
5. Orfale AG, Araújo PMP, Ferraz MB e Natajour J. Translation into Brazilian Portuguese, cultural adaptation and evaluation of the reliability of the disabilities of the arm, shoulder and hand questionnaire. Braz J Med Biol Rev. 2005;38(2):293-302. doi: 10.1590/S0100$\underline{879 \times 2005000200018}$

6. Lauridsen MC, Christiansen P, Hessov I. The effect of physiotherapy on shoulder function in patients treated surgically for breast cancer: a randomized study. Acta Oncol. 2005;44(5):449-57. doi: 10.1080/02841860510029905

7. Sousa E, Carvalho FN, Bergmann A, Fabro EAN, Dias RA, Koifman RJ. Funcionalidade de membro superior em mulheres submetidas ao tratamento do câncer de mama. Rev Bras Cancerol. 2013;59(3):409-417

8. Batiston AP, Santiago SM. Fisioterapia e complicações físico-funcionais após tratamento cirúrgico do câncer de mama. Rev Fisioter Pesq. 2005; 1 2(3):30-5.

9. de Jesus LA, Medrado ARAP. Análise de capacidade funcional e métodos de avaliação de membros superiores em mulheres submetidas ao tratamento de câncer de mama: uma revisão sistemática. Rev pesquisa em fisioterapia. 2015(5):286-299. doi: 10.17267/2238-2704rpf.v5i3.677

10. Pimenta CAM, Koizume MS, Teixeira MJ. Dor no doente com câncer: características e controle. Rev Bras Cancerol. $1997 ; 43(1): 21-44$.

11. Silva MD, Rett MT, Mendonça ACR, Junior WMS, Prado VM, Santana JM. Qualidade de Vida e Movimento do Ombro no Pós-Operatório de Câncer de Mama: um Enfoque da Fisioterapia. Rev Bras Cancerol. 2013;59(3):419-426. 